\title{
EDITORIAL
}

\section{Saúde: conhecer e divulgar, para avançar}

Em um ano como 2020, marcado por tentativas de mudança nas políticas nacionais de saúde mental no Brasil, e por questões de saúde física ocupando no resto do mundo, cria-se o ambiente propício para pensar o que sabemos sobre a saúde de nossa população.

Há carência de informações básicas sobre as condições de saúde de indígenas, quilombolas, moradores de comunidades e aglomerados, população em situação de rua, e LGBTQIA+, apenas para citarmos algumas.

Inúmeros aspectos da saúde dos brasileiros até o presente momento não receberam a atenção adequada por parte de governantes, legisladores ou pesquisadores. Faltam informações sobre a saúde física de pessoas com transtornos mentais, sobre o impacto do estigma nas populações LGBTQIA+, do impacto de medidas de promoção da saúde, redução de danos e de relações entre o adoecimento e condições culturais e econômico-sociais. 0 fato das informações existentes não serem compartilhadas ou entendidas pela população brasileira também representa uma lacuna.

Com as dimensões continentais do Brasil e os recentes desafios advindos da pandemia de COVID-19, pode-se argumentar que é difícil conhecer todas as realidades da população e que faltam verbas, notadamente para pesquisas. Mas raramente uma resposta simples é suficiente para uma pergunta complexa como a que envolve a saúde dos brasileiros.

A falta de investimento em pesquisa, as dificuldades logísticas e financeiras para prosseguir com investigações populacionais e longitudinais no país, o sucateamento (financeiro e de valorização social) da educação e dos serviços de saúde pública, a piora da qualidade da formação profissional com a mercantilização da educação, a adoção de práticas sem comprovação científica ou assumidamente pseudocientíficas como política pública em saúde, a falta de saneamento e outras condições básicas para manutenção da vida, a burocracia que envolve novas propostas de cuidados (de saúde física e mental) e a deficiência em comunicar a ciência para toda a população são aspectos que pesam na situação da saúde no país.

É necessário falar, pesquisar e planejar medidas sobre saúde. Esses debates precisam contar com a participação da comunidade acadêmica, de setores políticos estratégicos e de representantes comunitários, pois da junção de saberes e setores se farão as ações de promoção e cuidado em saúde para as diferentes realidades brasileiras.

Muitos pontos para a melhoria da saúde passam por decisões governamentais, mas alguns envolvem uma posição da academia. Há um desafio para que o ensino superior, em todos os seus níveis (graduação, lato sensu e stricto sensu) debata sobre saúde mental.

Profissionais de saúde poderão ter atuação mais direta, mas a tecnologia que será utilizada, as leis que regulam a atuação, a educação que reduzirá desinformação e adesão a pseudociência, a compreensão mais ampla que bem-estar gera saúde, faz imperativo que todas as áreas sejam envolvidas na discussão sobre saúde. As investigações têm mostrado, inclusive, que a saúde dos estudantes e dos profissionais precisa ser igualmente trazida para o debate.

Os governantes precisarão respeitar a ciência em todas as suas tomadas de decisão e isso não significa escolher o aspecto que corrobora aquilo que desejam. Enquanto isto, a academia precisa aprender a tornar a população agente da produção e divulgação desse conhecimento, o que trará maior significado para os estudos realizados, maior compreensão sobre como o conhecimento é produzido e o impacto de incluí-lo na vida cotidiana.

Nesse sentido, o presente número da REFACS colabora trazendo relatos de estudos desenvolvidos por pesquisadores de diferentes regiões do Brasil, os quais abordam saúde mental e políticas públicas em investigações e exemplos de intervenção. 
A linguagem usada ainda atende mais ao que a academia exige do que o que boa parte da população brasileira conseguiria compreender, mas é um passo importante para seguir pensando em saúde e ciência no país.

Espera-se que os temas explorados possam subsidiar debates, futuras pesquisas e intervenções para os mais diversos grupos populacionais. Além disso, espera-se seja reconhecida a importância da divulgação científica, para os pares e para aqueles que possam valer-se dos achados (e que, por vezes, ainda são vistos apenas como "participantes" ou "sujeitos de pesquisa"). Pública. Professora Adjunta e coordenadora do Programa de Pós Graduação em Psicologia da Universidade Federal do Triângulo 